\title{
AC 2007-1206: DIGITAL DESIGN PROJECT COMPETITION USING ADVANCED FPGA TECHNOLOGY AND HARDWARE DESCRIPTIVE LANGUAGES
}

\section{Mihaela Radu, Rose-Hulman Institute of Technology}

Clint Cole,

president DigilentInc, Pullman, WA

\section{Mircea Dabacan, Technical University of Cluj Napoca, Romania}

Dr. Mircea Dabacan received the Diploma Engineer (M.S.) degree in Electronics and Telecommunications Engineering from the Polytechnic Institute of Cluj-Napoca, Romania, in 1984, and a Ph.D. in Electronics Engineering from the Technical University of Cluj-Napoca, in 1998. Since 2001 he has been an Associate Professor with Technical University of Cluj-Napoca, Faculty of Electronics and Telecommunications and since 2005 he holds the position of Professor with the same university. He was a Visiting Professor at Washington State University, Pullman (1999-2000), and held a short Visiting appointment at Fachhochschule für Technik Esslingen, Germany (1993). He taught several undergraduate and graduate courses on Peripheral Equipment, Microprocessors, Data Acquisitions Systems and Design of High Performance Digital Circuits. He supervised more than 50 students for their B.Sc. and M.Sc. thesis projects. His current research interests include Data Acquisition Systems, sigma-delta analog-to-digital converters (ADCs), and programmable devices. He has authored or co-authored over 60 reviewed papers in international conference proceedings and journals, and three textbooks. 


\title{
Digital Design Project Competition using Advanced FPGA Technology and Hardware Descriptive Languages
}

\begin{abstract}
The majority of the undergraduate engineering courses in hardware areas such as Digital Design sequence of courses covers theory and usually have integrated laboratory, evaluating students' knowledge through exams, home-works, and practical laboratory exams. However, there is still a tremendous need for more innovative methods to reinforce the students' technical and practical knowledge, to meet all the learning objectives and to better prepare the students for the global industry's needs ${ }^{5}$.

Trying to organize and to integrate in a very packed curriculum a Digital Design Project Competition open to students presently and formerly enrolled in Digital Design courses is the idea being addressed in this paper. This paper presents the results of the on-going efforts trying to organize first edition of such a competition at Rose Hulman Institute of Technology, Terre Haute, IN.

The competition is sponsored by Digilent, Inc., Pullman, WA, a company producing state of the art FPGA boards. The emphasis of the competition is on conceptual design, implementation and validation of the projects using FPGA boards and Verilog as HDL.
\end{abstract}

\section{Introduction}

As the complexity of microelectronic systems is steadily increasing, the universities have to adapt their curricula to cope with the demands of research and development of future systems. So it is important that the students learn to use industrial tools and state of the art technology early in the curriculum. Continual advances in technology necessitate on-going updates and modifications to existing digital design teaching methods, techniques, so we try this new concept- a digital contest- in order to reinforce students' technical and practical knowledge, to meet all the learning objectives and to better prepare them for the demanding industry's needs ${ }^{1}$.

Trying to organize and to integrate in a very packed curriculum a Digital Design Project Competition open to Electrical and Computer Engineering and Computer Science students is the idea being addressed in this paper.

\section{Background and Motivation}

The idea of the competition was inspired by a similar and very successful experience in a European University, Technical University of Cluj-Napoca, Romania. At this university, two editions of a Digital Design contest were organized with extremely good results. They were sponsored by the same company, Digilent, Inc., as at RHIT. Students entered the competition with very creative and mature projects, and the results were beyond the expectations of local professors and sponsors, who traveled all the way from USA, to the city of Cluj, to attend the final phase of the competition and judge the students' projects. 


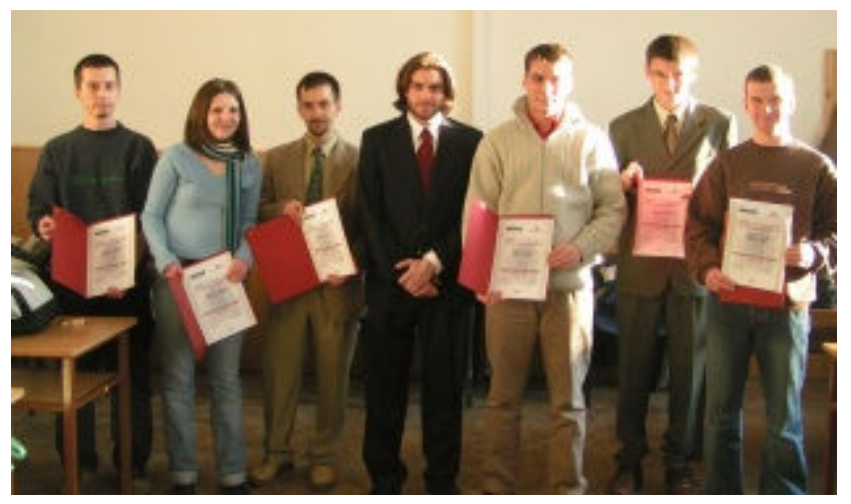

Fig.1 Winners of the Digilent Design Competition, first edition contest at TUCN, RO

Inspired by this successful experience, the first author of this paper decided to organize such a competition at Rose Hulman Institute of Technology, and asked Digilent, Inc for logistic support.

\section{Organizing the Competition, First Edition at RHIT}

The competition is sponsored by Digilent, Inc., which produces state of the art FPGA boards. The emphasis of the competition is on conceptual design, implementation and validation of the projects using FPGA boards and Verilog as HDL ${ }^{2}$.

Due to the specificity of the school, mainly dedicated to undergraduate education, the contest is open to undergraduate students, who will enter the competition with original projects, judged based on creativity, originality, feasibility, degree of difficulty.

The biggest challenge is to attract and stimulate the students who are already extremely busy and engaged in various scholastic and non-scholastic activities during the quarters. To motivate and attract the students, Digilent will post the projects accepted for the competition on their web page. The students enrolled in the contest will receive free boards donated by the same company, and they can keep them if they finalize their projects, regardless of the final prize or position in the competition. Another idea is to consider this experience as part of professional development, so this experience will count for credit hours. Of course, cash prizes will be awarded to the winning projects of the competition.

In terms of logistics and strategy, the initial idea was to have a "Call for Projects" in the fall quarter, to evaluate and accept/reject the projects in the winter quarter, and to have the final competition in the spring quarter. After careful consideration, and several discussions with Digilent staff and RHITstudents, a Call for competition was launched earlier this year, announcing: "Spring 2007 Digital Design Contest

Digilent ${ }^{\oplus}$, in partnership with Xilinx $x^{\circledast}$ Corporation and Rose Hulman Institute of Technology, launches the Spring 2007 Digital Design Contest, open to all ECE and CS students enrolled at RHIT. 
Cool Prizes! Grand Prize is 1000 USD (cash).

Grand Prize will be awarded to the best project using Nexys boards.

Rest of the prizes, valuing 1500 USD-total, to be decided by the jury of the competition.

Digilent will give you, at no cost, all the hardware that you need for your projects:

Nexys boards (based on Xilinx's Spartan-3 FPGA), JTAG programming cable, USB cable and a power supply. If your project meets the contest requirements, the hardware is yours to keep."

\section{Contest Requirements and Rules}

The projects requirements, as requested by the sponsoring company:

"-Because Digilent, Inc. designs and produces educational boards we're looking for cool, modular, fully-functional, open-source designs that really show-off these boards' features. We want reference designs that can teach engineering students new designs and skills. Since the boards are used by universities, corporations, and digital designers around the world, we want to showcase you and your winning project on our website and inspire students (and impress employers) worldwide".

-Projects must be fully functional and all features need to behave in a consistent manner. Projects must be well-structured. The upper-level hierarchical level is a structural file corresponding to the project block diagram. The instantiated components are described in lower level hierarchical files.

-Projects must be open source. It is critical to provide comprehensive comments so that users can easily understand the structure and logic of your project in order to make their own modifications. User manual and additional design documents (state diagrams, transition tables, UCF files, etc.) are required.

-Contestants will make a public presentation and a practical demonstration. The jury will evaluate projects based on relevancy, complexity, innovation, use of good design practice, clarity of documentation, and quality of presentation ${ }^{2}$, ."

Two divisions were organized: a higher level division for students formerly or presently enrolled in advanced classes in Digital Design and a lower level division, for students formerly or presently enrolled in introductory classes in Digital Design.

-The project will count for 2 (two) professional development credits. The first three students who will qualify on the top positions will receive 3 (three) credit hours for this contest. The number of credit hours was decided by the ECE department.

\section{Possible Project Categories}

Examples of possible project categories, but not limited to:

Image Acquisition and Processing: Build an infrared or visible image acquisition and processing system, perhaps with edge detection, or image capture and analysis for any interesting artifacts. 
Signals and Sensors: Add Pmods to Nexys ${ }^{\mathrm{TM}}$ boards to build JTAG diagnostic tools, signal capturing with FFT analysis and inverse transformation, or a variety of other interesting projects. General Control Systems: Build a feedback control system using the Nexys ${ }^{\mathrm{TM}}$ board to illustrate feedback control of a switch-mode power supply, or of a motorized application of some sort, focusing on educational demonstrations and on student learning activities.

Audio Projects: Create virtual instruments (such as a laser harp), voice-processing, or FX processors. Or build a voice message recorder/player with a microphone, ADC, FPGA memory, DAC, amplifier, speaker.

Motor Control: Consider any useful, innovative or artistic use of servo and/or DC motors. As examples, create a mobile robot using Nexys ${ }^{\mathrm{TM}}$ board for control, DC motors for drive, and servos for accessory devices (like grabbers, steering, etc.) Add sensors or intelligent control to your robot using Pmods.

\section{Contest development}

As the Call for Projects was launched, several students responded promptly, showing interest to participate. So far, 35 students enrolled initially in both divisions. At this point in time, 30 students presented their project ideas for the competition and they are officially enrolled in the competition. The range of their project ideas is wide from computer/editor/graphics, music and image processing to videogames.

Selected examples from the upper division- "Advanced Security System”, "Laser Harp with variable volume and tone", "Medical Applications Using an FPGA Board", "Low Cost Oscilloscope", "Secret message encoder", "Audio Signal Equalizer", "Spectrum Analyzer with VGA Display", Reactive Light Machine", "Voice message recorder/player".

Selected examples from the lower division: "Gumball Sorter", Monochromatic Laser Projector, "Virtual MIDI keyboard”, Smart Traffic Light Control System”, "Ultra Escape video game”,etc.

At this point in time, students' project descriptions are evaluated by a group of RHIT professors and suggestions are made individually. Students already received their Nexys boards and they are preparing for the final competition, which will take place early May.

An active web page of the digital design competition is maintained, showing the latest news in the development of the competition:

http://www.rose.hulman.edu/class/ee/radu/DIGILENT/ 


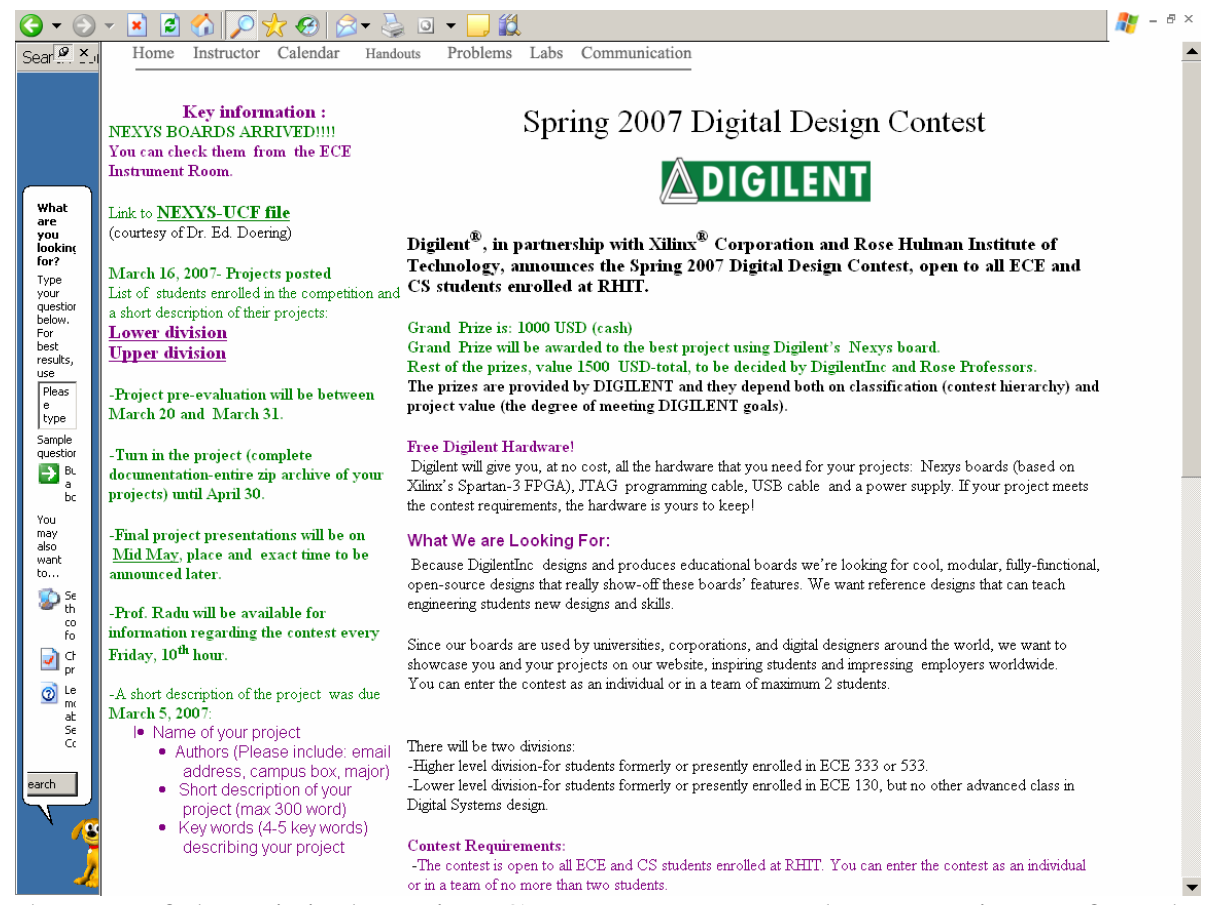

Fig.2. The webpage of the Digital Design Contest at Rose Hulman Institute of Technology

\section{Conclusions and Future Work}

The authors of this paper have reasons to believe that this competition will give the students the opportunity to demonstrate their creativity, problem solving skills, competitive skills and motivation to work for a project outside class requirements, for their benefit. If this edition will prove to be successful, possible a second one will be organized at RHIT, followed by an international digital design competition between students from different universities, located in Europe and USA.

\section{Bibliography}

1. Ardian Greca, J. Harris "WIP-Integrating Student's Research Project into the Digital Logic design Course to Enhance Learning", 35 ${ }^{\text {th }}$ IEEE FIE Conference, Indianapolis, 2005.

2. Hardy J. Pottinger "Design Contests as Class Projects: Are They Worth the Effort?" 2001 International Conference on Microelectronic Systems Education (MSE'01)

3. Mihaela Radu, Archana Chidanandan "Comprehensive Design projects Integrated in Digital Systems and Computer Architecture", EWME06, European Workshop on Microelectronics Education, Stockholm, Sweden www.digilentinc.com

www.utcluj.ro

www.rose-hulman.edu 